\title{
Constitutive expression of bergaptol $O$-methyltransferase in Glehnia littoralis cell cultures
}

Aya Ishikawa $^{\mathrm{a}} \cdot$ Tatsuya Kuma $^{\mathrm{b}} \cdot$ Hiroyuki Sasaki $^{\mathrm{b}} \cdot$ Nobuhiro Sasaki ${ }^{\mathrm{c}} \cdot$ Yoshihiro Ozeki $^{\mathrm{c}} \cdot$ Nobuyuki Kobayashi $^{\mathrm{a}} \cdot$ Yoshie Kitamura $^{\mathrm{b}}{ }^{*}$

${ }^{a}$ Graduate School of Biomedical Sciences, Nagasaki University, Nagasaki 852-8521, Japan

${ }^{\mathrm{b}}$ Faculty of Environmental Studies, Nagasaki University, Nagasaki 852-8521, Japan

${ }^{\mathrm{c}}$ Department of Biotechnology, Tokyo University of Agriculture and Technology, Tokyo, Japan

*Corresponding author

Yoshie Kitamura

address: Faculty of Environmental Studies, Nagasaki University, Bunkyo-machi 1-14, Nagasaki 852-8521, Japan.

Tel/fax: +81-95-819-2759

e-mail:k-yoshie@nagasaki-u.ac.jp 


\section{Abstract}

We investigated whether exogenously supplied precursors of bergapten, namely umbelliferone, psoralen and bergaptol, could be utilized to produce bergapten without elicitation in Glehnia littoralis cell suspension cultures. The levels of added psoralen and bergaptol in the medium soon decreased, and this was followed by the detection of bergapten in both culture fluid and cells. Umbelliferone was also incorporated but in this case no bergapten was produced; instead, skimmin, umbelliferone monoglucoside, was detected. To determine whether conversion of psoralen to bergapten was due to enzyme induction by precursor feeding, the transcript accumulations and enzyme activities of bergaptol $O$-methyltransferase (BMT, EC 2.1.1.69), which catalyzes the last step of bergapten synthesis, and of phenylalanine ammonia-lyase (PAL, EC 4.3.1.5), which catalyzes the initial step of the phenylpropanoid biosynthetic pathway and is known as a marker enzyme of elicitation, were examined. The results showed that both the expression and the activity of BMT were always detected in all cells, including control cells. Since PAL was slightly induced in the cells supplied with/without precursors, phenylethyl alcohol (PEA, a competitive inhibitor of PAL) was applied to suspension cells prior to the addition of psoralen. PAL activity was effectively inhibited by PEA at $1-5 \mathrm{mM}$ concentrations. Under these conditions, PEA did not affect bergapten production by cell cultures fed with psoralen at all. These results demonstrate that BMT is constitutively expressed in G. littoralis cell cultures.

Keywords bergaptol O-methyltransferase (BMT) · constitutive expression · furanocoumarin biosynthesis $\cdot$ cell culture $\cdot$ Glehnia littoralis 
Abbreviations BMT: bergaptol $O$-methyltransferase $\cdot$ COMT: caffeic acid $O$-methyltransferase DMSO: dimethyl sulfoxide $\cdot P A L$ : phenylalanine ammonia-lyase $\cdot P E A$ : phenylethyl alcohol $\cdot S A M$ : S-adenosyl-L-methionine $\cdot X M T$ : xanthotoxol $O$-methyltransferase

\section{Introduction}

Furanocoumarins are a class of potent phytoalexins (Ozçelik et al. 2004; Smith et al. 2004; Wong and Kitts 2006) and allelochemical compounds (Stevenson et al. 2003) produced by plants of the Apiaceae, Rutaceae, Moraceae and Fabaceae (Franke et al. 2001; Milesi et al. 2001; Sidwa-Gorycka et al. 2003). In these plants, the most abundant linear furanocoumarins are psoralen, bergapten, xanthotoxin and isopimpinellin (Bourgaud et al. 2006). Some of these compounds are used clinically in the treatment of skin diseases such as leukoderma and psoriasis (Anderson and Voorhees 1980; Maisch, 2007) and they may have potential as drugs for the treatment of multiple sclerosis (Kawase et al. 2005; Strauss et al. 2000), although ingestion may be injurious to health (Hauffe et al. 1986; He et al. 1998). One of the pharmacological effects of such furanocoumarins is a photosensitizing action, by which interstrand cross-links are formed in native DNA (Cole, 1970). Other effects are the inactivation of cytochrome $\mathrm{P}_{450}$ enzymes by mechanism-based inactivation (Fouin-Fortunet et al. 1986) and the blockage of potassium channels (Bohuslavizki et al. 1994). The biosynthetic pathway of bergapten has been established, starting from phenylalanine via cinnamic acid, umbelliferone, demethylsuberosin, (+)-marmesin, psoralen and bergaptol (Hahlbrock and Scheel 1989; Larbat et al. 2007; Mo and Sung 2006) (Fig. 1). In most furanocoumarin-producing plants, except for Ruta graveolens (Ekiert et al. 2001), this pathway was highly inducible by biotic (Hamerski et al. 1990; Tietjen et al. 1983) and abiotic (Zangerl and Berenbaum, 1994) stresses.

Glehnia littoralis (Apiaceae) is a perennial herb growing on the seashore in East Asia. The roots and rhizomes of this plant are used as traditional Chinese and Japanese herbal medicines and contain coumarins (include furanocoumarins) and coumarin glycosides (Kitajima et al. 1998; Sasaki et al. 
1980; Yuan et al. 2002). From G. littoralis petiole, we have established two types of cells: high-yielding, anthocyanin-producing (violet) cells and non-producing (white) cells (Miura et al. 1998). Using the white cells, we showed that phenylalanine ammonia-lyase (PAL) was induced de novo by yeast-extract treatment and this was followed by the production of umbelliferone and bergapten in the culture medium, although umbelliferone was only detected transiently (Ishikawa et al. 2005). In the violet cells, on the other hand, the transient suppression of PAL, which is constitutively expressed, caused a decrease in anthocyanin production; however, no bergapten was induced by yeast-extract treatment. Further survey revealed that the violet cells produced umbelliferone and released it into the culture medium continuously, with or without elicitation (Ishikawa et al. 2005). Although it is quite hypothetical to compare different cell cultures without experimental evidence, we presumed that in intact plants of G. littoralis, violet cells and white cells probably possess metabolically similar properties to epidermal cells (anthocyanin-producing cells) and their adjacent, parenchymatous cells (furanocoumarin-producing cells), respectively. If white cells utilize the umbelliferone produced by violet cells and convert it to bergapten, bergapten will be produced without elicitation.

In this report, we investigate whether G. littoralis white suspension cells can take up exogenous coumarin precursors including umbelliferone, psoralen and bergaptol and convert these precursors into bergapten without de novo synthesis. We discover that G. littoralis white suspension cells convert psoralen and bergaptol, but not umbelliferone, into bergapten. In addition, the conversion is not induced by coumarin feeding, but occurs due to constitutively active enzymes involved in the biosynthetic pathway.

\section{Materials and methods}

Chemicals

Umbelliferone, caffeic acid and o-coumaric acid were purchased from Nakarai chemicals (Kyoto, 
Japan). Phenylethyl alcohol (PEA), 4-methylumbelliferone, L-phenylalanine and cinnamic acid were from Wako Pure Chemical Industries (Osaka, Japan). Psoralen, bergaptol, xanthotoxol and bergapten were from Extrasynthese (Genay, France). S-adenosyl-L-methionine (SAM) was from Sigma-Aldrich (St. Louis, USA). Skimmin was kindly provided by Prof. Masanori Kuroyanagi (Prefectural University of Hiroshima). Other chemicals were of the highest quality commercially available.

Cell cultures, culture conditions and administration of coumarins

Cell suspension cultures of white calli of Glehnia littoralis Fr. Schmidt ex Miquel were established and sustained as previously reported (Kitamura et al. 2002). They were maintained in $25 \mathrm{ml}$ of Murashige and Skoog (1962) basal medium containing 2,4-dichlorophenoxyacetic acid (1 $\mu \mathrm{g} / \mathrm{ml})$ and kinetin $(0.01 \mu \mathrm{g} / \mathrm{ml})$ (Miura et al. 1998) in a $100 \mathrm{ml}$ of Erlenmeyer flask at $25^{\circ} \mathrm{C}$ at $80 \mathrm{rpm}$ in the dark. Cultures ca. 2 weeks old were used for the experiment. The cells were collected by vacuum filtration, and then $2.5 \mathrm{~g}$ of cells were inoculated into the same fresh medium. Umbelliferone, psoralen, bergapten $(120 \mu \mathrm{M}$ at final concentration) and bergaptol (40 $\mu \mathrm{M}$ at final concentration) dissolved in dimethyl sulfoxide (DMSO) were added to the medium beforehand. As a control, only DMSO was added to the cell cultures. They were incubated under the above-mentioned conditions and then cultures were harvested by vacuum filtration after 3, 6, 9, and $24 \mathrm{~h}$. Collected cells and media were stored at -70 and $-20^{\circ} \mathrm{C}$, respectively, until analysis.

To study the inhibition of PAL activity, suspension cells were transferred into fresh medium containing 1 and $5 \mathrm{mM}$ PEA (Mo and Sung 2006), and then psoralen was added to the culture medium.

Analysis of coumarins

Coumarin contents were determined as previously described (Kitamura et al. 1998), with some 
modifications. Coumarins were extracted from $0.5 \mathrm{~g}$ of frozen, powdered cells with $1.6 \mathrm{ml}$ of methanol. The extract was vortexed for $2 \mathrm{~min}$ and then centrifuged at $6,600 \mathrm{~g}$ for $10 \mathrm{~min}$. The supernatant was collected and made up to a volume of $2 \mathrm{ml}$ with methanol for analysis. Cultured medium (ca. $20 \mathrm{ml}$ ) was extracted with $20 \mathrm{ml}$ ethyl acetate; $10 \mathrm{ml}$ of this was removed and evaporated to dryness under vacuum, and the residue was redissolved in $1 \mathrm{ml}$ of methanol for analysis.

4-Methylumbelliferone $(5 \mathrm{mM}, 50 \mu \mathrm{l})$ was added to each sample as an internal standard before extraction. Coumarins were separately quantitated by HPLC (Shimadzu LC-10). A Finepak SIL C18S column (4.6 mm i.d. x $150 \mathrm{~mm}$; Jasco, Japan) was used and the column was eluted with a step gradient from water (A) and acetonitrile (B), starting at $20 \%$ B for 10 min, and followed by $30 \%$, $35 \%, 40 \%$ and $20 \% \mathrm{~B}$, respectively, after $10 \mathrm{~min}$ intervals. Elution, at a flow rate of $1 \mathrm{ml} / \mathrm{min}$ at $40^{\circ} \mathrm{C}$, was monitored with a UV-visible detector at $254 \mathrm{~nm}$ and a photodiode array detector. Retention times of coumarins under these conditions were as follows: umbelliferone, $8.9 \mathrm{~min}$; 4-methylumbelliferone, $14.2 \mathrm{~min}$; bergaptol, $18.2 \mathrm{~min}$; psoralen, $24.2 \mathrm{~min}$; bergapten, $30.8 \mathrm{~min}$. Skimmin (umbelliferone monoglucoside) was also analyzed on a TSK gel ODS-120A column (4.6 mm i.d. x $150 \mathrm{~mm}$; Tosoh Corporation, Japan) with gradient elution from $1 \mathrm{mM}$ acetic acid (A) and acetonitrile (B), starting at $12 \% \mathrm{~B}$ for $5 \mathrm{~min}$, and followed by $40 \% \mathrm{~B}$ for $15 \mathrm{~min}$. Other conditions were same to above. Skimmin was eluted at $4.5 \mathrm{~min}$. TLC was also carried out on silica gel $\left(\mathrm{GF}_{254}\right.$, Merck) with ethylacetate-methanol-water (100:13.5:10) as mobile phase, for identification of skimmin. Spots were detected under UV-illumination by spraying $10 \%$ sulphuric acid followed by heating. Rf-values of skimmin and umbelliferone were 0.51 and 0.91 , respectively.

\section{Assay of enzyme activity}

\section{Extraction of proteins}

Protein extraction was carried out as previously reported (Kitamura et al. 1998), with some modifications. The crude enzyme preparation was performed at $0 \sim 4^{\circ} \mathrm{C}$. Frozen cells $(0.5 \mathrm{~g})$ were mixed with polyvinylpolypyrrolidone $(0.2 \mathrm{~g})$ and homogenized in $1.5 \mathrm{ml}$ of $100 \mathrm{mM}$ potassium 
phosphate buffer (KPi; pH 8.0), containing $1.4 \mathrm{mM} \beta$-mercaptoethanol, in a mortar. After centrifugation at 6,600 $\mathrm{g}$ for $15 \mathrm{~min}, 0.5 \mathrm{ml}$ of Dowex $1 \times 4\left(\mathrm{Cl}^{-}\right.$form, The Dow Chemical Co., USA), equilibrated with $100 \mathrm{mM} \mathrm{KPi} \mathrm{(} \mathrm{pH} 8.0$ ), was added to the supernatant, and the mixture was kept on ice for $20 \mathrm{~min}$ (shaken every $5 \mathrm{~min}$ ). After centrifugation at 6,600 g for $15 \mathrm{~min}$, the supernatant was used as crude enzyme solution. Protein amounts were determined with Bio-Rad protein assay (Bio-Rad Laboratories, Japan) by Bradford's (1976) method, using bovine serum albumin as a standard.

Assay of PAL activity

Assay of PAL (EC 4.3.1.5) activity was as previously reported (Kitamura et al. 1998), with some modifications. The reaction mixture comprised $0.1 \mathrm{ml}$ of $100 \mathrm{mM}$ potassium borate buffer $(\mathrm{pH} 8.7)$, containing $0.5 \mu \mathrm{mol}$ phenylalanine, and $0.2 \mathrm{ml}$ of crude enzyme solution. Following incubation at $30^{\circ} \mathrm{C}$ for $60 \mathrm{~min}$, the reaction was terminated by adding $50 \mu \mathrm{l}$ of $5 \mathrm{M} \mathrm{HCl}, 15 \mu \mathrm{l}$ of $5 \mathrm{mM}$ o-coumaric acid was added as an internal standard, and the reaction product was extracted with diethyl ether $(0.5 \mathrm{ml})$. After centrifugation $(6,600 \mathrm{~g}, 2 \mathrm{~min})$, organic layer was collected and evaporated in vacuo. The residue was redissolved in methanol $(0.1 \mathrm{ml})$ for analysis. The blank was obtained by the same method as described above, but using boiled enzyme.

For measurement of the PAL reaction product, a TSK gel ODS-120A column (4.6 mm i.d. x 150 $\mathrm{mm}$; Tosoh, Japan) was used. The column was eluted with $25 \%$ acetonitrile in acetic acid/water $(1 / 730, \mathrm{v} / \mathrm{v})$ for $20 \mathrm{~min}$. Elution at a flow rate of $1 \mathrm{ml} / \mathrm{min}$ at $40^{\circ} \mathrm{C}$ was monitored with a UV-visible detector at $254 \mathrm{~nm}$ and a photodiode array detector.

Assay of bergaptol $O$-methyltransferase (BMT) activity

BMT (EC 2.1.1.69) activity was assayed as described (Hauffe et al. 1986; Hehmann et al. 2004). A reaction mixture of $100 \mathrm{mM} \mathrm{KPi}(\mathrm{pH} 8.0,50 \mu \mathrm{l})$, containing $20 \mathrm{mM}$ sodium ascorbate, $0.25 \mathrm{mM}$ bergaptol and $0.2 \mathrm{mM} \mathrm{SAM}$, together with $0.2 \mathrm{ml}$ of crude enzyme solution was incubated at $40^{\circ} \mathrm{C}$ for $60 \mathrm{~min}$. The reaction was terminated by adding $50 \mu \mathrm{l}$ of $5 \mathrm{M} \mathrm{HCl}, 50 \mu \mathrm{l}$ of $5 \mathrm{mM}$ umbelliferone 
was added as an internal standard, and the reaction product was extracted with ethyl acetate $(0.5 \mathrm{ml})$. After centrifugation $(6,600 \mathrm{~g}, 2 \mathrm{~min})$, the organic layer was collected and evaporated in vacuo. The residue was dissolved in methanol $(0.5 \mathrm{ml})$ and the reaction product was determined as described above for the analysis of coumarins.

RNA isolation, PCR cloning and heterologous expression

Total RNA was isolated from frozen white cells and roots of G. littoralis (100 mg) using a RNeasy Plant Mini Kit (Qiagen, Tokyo, Japan) following the manufacturer's instructions. The cDNA fragments were generated by RT-PCR amplification using a TaKaRa RNA PCR Kit (AMV) Ver.3.0 (Takara Bio, Japan). The primers were designed from Ammi majus BMT sequence based on Hehmann et al. (2004) (GenBank accession no. AY443006), corresponding to conserved amino acid sequences of plant OMTs (Frick and Kutchan 1999). The cDNA fragments were cloned and sequenced, and full length clones were generated by TaKaRa 3'- and 5'-Full RACE Core Sets (Takara Bio, Japan), using gene-specific primers. Cloning of the PCR products was performed by TOPO TA Cloning (Invitrogen, Japan). The cDNA sequences were subjected to BLAST and FASTA searches (GenBank) and alignments with the clustalW algorithm (DNA Data Bank of Japan ).

The ORF of putative BMT was amplified with 5'-primers providing CACC before the start codon and 3'-primers to the stop codon before it was cloned into the pENTR/TEV/D-TOPO vector (Invitrogen, Japan). Cloning was confirmed by DNA sequencing. Using LR clonase (Invitrogen, Japan), it was subcloned into expression vector pDEST 17 for functional expression in E. coli strain BL21(DE3) (Novagen, Germany). The expression was induced by the addition of $1 \mathrm{mM}$ isopropyl thio- $\beta$-D-galactoside at $16^{\circ} \mathrm{C}$ for $4 \mathrm{~h}$. After harvested by centrifugation $(3,000 \mathrm{xg}, 15 \mathrm{~min})$, the cells were lygated by ultrasonification. The supernatant obtained by centrifugation $(12,000 \mathrm{xg}, 30 \mathrm{~min})$ was used for BMT assay as mentioned above. To determine the substrate specificity, xanthotoxol O-methyltransferase (XMT) (EC 2.1.1.93) and caffeic acid O-methyltransferase (COMT) (EC 2.1.1.68) activities were also assayed using xanthotoxol and caffeic acid as the substrate, respectively, according to the similar method mentioned above (BMT activity). For COMT activity, incubation 
was carried out at $32^{\circ} \mathrm{C}$ in the $100 \mathrm{mM} \mathrm{KPi}(\mathrm{pH} 7.5)$. Time of incubation and the amount of protein were adjusted using various conditions for kinetic assays.

Cloning of partial cDNA fragments derived from GIPAL was performed by 3'-RACE using the primers corresponding to conserved amino acid sequences of PALs previously deposited in databases. For control of RT-PCR, Gl polyubiquitin (UBI) partial cDNA was also sequenced in the same way. GenBank accession numbers of GIPAL, GIBMT and GIUBI are AB374257, AB363638 and AB363637, respectively.

\section{RT-PCR}

The sequences of specific primers for GlPAL, GlBMT and GIUBI, which were used for RT-PCR, were as follows: PAL forward, 5'-GAAATCTTGAAACTCATGTCTAC-3'; PAL reverse, 5'-CATCAATGGGTAGGTTGC-3'; BMT forward, 5'-GTGTGGTTCATCTTGATGCT-3'; BMT reverse, 5'-GTGGCCCTTATTGCATATTT-3'; UBI forward, 5'-TCACCCTGGAGGTTGAGAG-3'; UBI reverse, 5'-GACGCAACACAAGGTGAAGA-3'. RT-PCR was performed using the PC708 programmed temperature control system (Astec, Japan)). The reverse transcription reaction was carried out at $51^{\circ} \mathrm{C}$ for $15 \mathrm{~min}, 99^{\circ} \mathrm{C}$ for $5 \mathrm{~min}$ and $5^{\circ} \mathrm{C}$ for $5 \mathrm{~min}$, according to the manufacturer's protocol. The PCR reaction was initiated with a denaturation at $94^{\circ} \mathrm{C}$ for $2 \mathrm{~min}$, followed by 25 cycles of $94^{\circ} \mathrm{C}$ for $30 \mathrm{~s}, 60^{\circ} \mathrm{C}$ for $30 \mathrm{~s}$, and $72^{\circ} \mathrm{C}$ for $30 \mathrm{~s}$. RT-PCR products were loaded onto $1.5 \%$ (w/v) agarose gels and stained with ethidium bromide.

\section{Results}

Uptake of coumarins and conversion into bergapten

To investigate whether white cells could take up and utilize exogenous precursors to produce 
bergapten without yeast-extract treatment, suspension cells ca. 2 weeks old were supplied with umbelliferone, with psoralen or with bergaptol and then incubated for 3, 6, 9, and $24 \mathrm{~h}$. HPLC analysis showed that psoralen and bergaptol almost disappeared after $24 \mathrm{~h}$ and that, concurrently, bergapten became detectable in the culture medium. Umbelliferone also disappeared, but in this case bergapten was not detected (data not shown). Time courses in the culture medium and in the cells showed that the amount of psoralen decreased gradually in the culture medium (Fig. 2, upper) and that it could be detected temporarily (peaking at $3 \mathrm{~h}$ ) in the cells (Fig. 2, lower). Bergaptol, by contrast, completely disappeared from the medium after $3 \mathrm{~h}$, but was not found in the cells (data not shown). In both cases, however, bergapten began to be detectable at $3 \mathrm{~h}$, both in the culture medium and in the cells, and the amounts increased until $24 \mathrm{~h}$ (Fig. 2). Conversion rates of psoralen and bergaptol after $24 \mathrm{~h}$ were $22.3 \%$ and $16.0 \%$, respectively. The bergapten content in the culture medium was higher than that in the cells at all time points (with psoralen feeding, 2.4 fold higher; with bergaptol feeding, 3.8 fold higher; each determined after $24 \mathrm{~h}$ ).

Like psoralen, umbelliferone supplied in the culture medium diminished gradually and could be detected temporarily in the cells. However, in this case no bergapten was detectable either in the medium or in the cells. To know the fate of umbelliferone, the cell extracts were again examined by HPLC under different conditions, showing that a more polar compound was newly produced by feeding of umbelliferone. Since umbelliferone administered to Ruta graveolens, Conium maculatum, Heracleum lanatum and Angelica archangelica was in each case rapidly converted into its monoglucoside, skimmin (Brown and Steck, 1973), the polar compound was likely to be skimmin. Therefore, the metabolite was compared by co-chromatography (HPLC and TLC) with authentic skimmin. Retention time, absorption spectrum and Rf-value of the polar compound were in good agreement with those of skimmin. Acid hydrolysis of both skimmin and its candidate on a silica gel plate caused fluorescence under UV-illumination, which was characteristic to umbelliferone, demonstrating that umbelliferone was converted to skimmin in G. littoralis cells. Quantitative analysis indicated that umbelliferone diminished from the culture medium was almost recovered from the cell extracts as skimmin (Fig. 3). 
Enzyme activities and gene expressions of PAL and BMT

Precursor-feeding experiments suggested that suspension cells supplied with psoralen or with bergaptol produced bergapten in the absence of yeast-extract elicitation, suggesting that both psolaren 5-monooxygenase, leading to bergaptol, and BMT, leading to bergapten, could be constitutively active. However, the possibility remained that the full set of biosynthetic pathway enzymes was induced by feeding these chemicals. To examine this possibility, we determined the enzyme activity and gene expression of PAL, which catalyses the first step of the phenylpropanoid pathway and is an elicitation marker, and of BMT, which was chosen because whereas psoralen 5-monooxygenase has not yet been cloned from any plants, the cloning of BMT has been reported in Ammi majus (Hehmann et al. 2004). For this experiment, the cloning of G. littoralis BMT was carried out using primers designed from the A. majus BMT sequence (GenBank accession no. AY443006), corresponding to conserved amino acid sequences of plant OMTs (Frick and Kutchan 1999). The putative GIBMT clone that was obtained, whose size was $1416 \mathrm{bp}$, encoding 359 amino acids (GenBank accession no. AB363638), showed the highest values of identity (86.9\%) and similarity (95.0\%) with AmBMT, whereas the identity and similarity of GIBMT with AmCOMT were $65.9 \%$ and $88.8 \%$, respectively. GlBMT was further confirmed by functinal expression in recombinant E.coli. Among various OMTs, XMT and COMT were representatively chosen for determination of substrate specificity; BMT, XMT and COMT activities were assayed using the crude protein solution, revealing that bergaptol was only accepted as the substrate (Table 1). GIPAL as well as GIUBI (GenBank accession nos. AB374257 and AB363637) were partially cloned and sequenced for this experiment.

PAL activity was not detected at $0 \mathrm{~h}$; however, it was then subtly induced and peaked at $6 \sim 9 \mathrm{~h}$, although its activity in the cells fed with coumarins was lower than that in the control cells throughout the experiment. BMT activity was relatively low in comparison to PAL activity, but detectable in all samples, including $0 \mathrm{~h}$ (Fig. 4). It seemed to be slightly induced by psoralen feeding, 
but there appeared to be relatively little effect of either coumarin feeding or incubation period. Gene expression of PAL and BMT was determined semi-quantitatively by RT-PCR, using G. littoralis specific primers; GIUBI was used as a control. The results showed a pattern similar to that of the enzyme activities; thus, $P A L$ transcript was not detected at $0 \mathrm{~h}$, but was induced transiently from 3-9 $\mathrm{h}$, followed by a decrease of transcript accumulation at $24 \mathrm{~h}$, whereas BMT transcripts were always detected, even at $0 \mathrm{~h}$, regardless of whether psoralen was supplied (Fig. 5). No difference of gene expression was observed in relation to the coumarin used (data not shown).

Effect of PAL inhibition on bergapten production

On account of the detection of a low level of PAL induction, there remained the possibility that induced PAL might affect uptake of psolaren and its conversion rate into bergapten. To avoid the influence of PAL induction, PEA (a competitive inhibitor of PAL) was added to cell cultures prior to the addition of psoralen. A preliminary experiment revealed that, at $9 \mathrm{~h}$ after treatment, PAL activity in suspension cells was sufficiently inhibited (50 - 90\%) by 1- $5 \mathrm{mM}$ of PEA, and this range of PEA concentrations had no apparent effect on BMT activity (Table 2). We therefore pretreated white cell cultures with these concentrations of PEA, and then psoralen feeding was performed as before (Fig. 2). It appeared that the treatment of cell suspensions with the PAL inhibitor, PEA, did not affect bergapten production at all.

\section{Discussion}

Most plants accumulating furanocoumarins have a highly inducible biosynthetic pathway, which can be triggered by various biotic (Hamerski and Matern 1988b) and abiotic (Zangerl and Berenbaum, 1994) stresses. Each of the enzyme reactions from umbelliferone to bergapten was demonstrated in vitro with Ammi majus (Hamerski and Matern 1988a; 1988b; Hamerski et al.1990; Hauffe et al. 
1986) and/or Petroselinum crispum (Hauffe et al. 1986; Tietjen and Matern, 1983; Wendorff and Matern, 1986) extracts derived from elicitor-induced cells. In all cases, non-induced control cultures showed no enzyme activity at all. Similarly, furanocoumarins were also induced in G. littoralis white cell and shoot cultures by yeast-extract treatment (Ishikawa et al. 2007; Kitamura et al. 1998). However, it is noteworthy that crude enzymes from non-elicited suspension cells showed apparent BMT activity, regardless of the addition of coumarins (Fig. 4). Although PAL in these cells was slightly induced by precursor feedings, this was to the same level as in control cells (Fig. 4). This induction must be due to a dilution effect of the culture medium (Takeda et al. 2002) and/or an effect of DMSO used as a solvent for coumarins. It was revealed through the inhibition of PAL activity by PEA that this induced PAL did not relate to bergapten synthesis at all. Thus, bergapten was derived from the conversion of exogenous psoralen without elicitation. The accumulations of BMT and PAL transcripts showed patterns similar to those of the corresponding enzyme activities (Figs. 4 and 5). BMT transcript was detectable at $0 \mathrm{~h}$, whereas PAL was not. All these results support the conclusion that BMT, but not PAL, is constitutively expressed in G. littoralis cell suspension cultures.

Previously, it has been reported using culture systems that Ruta graveolens (Rutaceae) shoots cultured in stationary liquid phase produce furanocoumarins and umbelliferone (Ekiert et al. 2001). Calli, cell suspensions and hairy roots of Ammi majus (Apiaceae) produced umbelliferone, but not furanocoumarins (Królicka et al. 2001). Sidwa-Gorycka et al. (2003) tried to cultivate these two plant materials in the same experimental device to know if the umbelliferone produced by A. majus cultures could serve as a substrate for furanocoumarin metabolism in $R$. graveolens. Their examination showed that a higher amount of xanthotoxin was detected in the co-culture system than in the single culture system, suggesting that the biosynthetic pathways of the different types of cultures were able to interact with each other. Because our G. littoralis violet cells produce and release umbelliferone into the culture medium (Ishikawa et al. 2005), we expected initially that white cells would utilize umbelliferone to produce bergapten, as is the case mentioned above. However, exogenous umbelliferone was not converted to bergapten, although it was taken up by G. littoralis suspension cells. Instead, skimmin, umbelliferone monoglucoside, was detected in the cell extracts 
(Fig. 3), as reported previously (Brown and Steck, 1973). In G. littoralis cell cultures, the step from umbelliferone to demethylsuberosin must be strictly regulated and be a second rate-limiting step, because even when the bergapten biosynthetic pathway was induced by elicitation, umbelliferone, but not other intermediates, was temporarily detected in the culture medium. Probably, skimmin functions as a metabolic pool of umbelliferone in G. littoralis cell cultures.

Nicotiana tabacum T-13 cells synthesize scopoletin (6-methoxy-7-hydroxycouomarin) as a phytoalexin, and in this system scopoletin in the culture medium was taken up by the cells and accumulated as its glucoside form, scopolin. This uptake involves the 7-hydroxycoumarin-specific transporter (Taguchi et al. 2000). Neither coumarin (no hydroxyl group) nor 6,7-dimethoxycoumarin (methylated at the 7-hydroxyl group) was taken up. This result suggests that in the case of G. littoralis cells, umbelliferone and furanocoumarins were taken up by different transporters and entered into different metabolic processes, leading to skimmin and bergapten, respectively. The transport mechanism for furanocoumarins is probably specific for furanocoumarin-producing plants. Psoralen administered to cultured cells of Arabidopsis thaliana and Duboisia leichhardtii, neither of which produces furanocomarins, remained exclusively in the culture medium (data not shown).

In this report, we have demonstrated that BMT is constitutively active in G. littoralis suspension cells by a combination of precursor-feeding experiments, assay of the enzyme activity and detection of BMT transcripts. Neither PAL/BMT gene expressions nor enzyme activities were induced significantly by psoralen addition, although bergapten was produced. Furthermore, no effect on bergapten formation was observed even when PAL activity was artificially inhibited. These results indicate that G. littoralis suspension cells can be used as a potential bioreactor to produce bergapten by supply of psolaren.

\section{Acknowledgements}

We thank Dr. Nicholas Walton (IFR, UK) for kind English edition of the text. Skimmin used in our 
study was kindly gifted by Prof. Masanori Kuroyanagi (Prefectural University of Hiroshima). This work was supported in part by a Grand-in-Aid $(\mathrm{C}, 18580255)$ from the Japan Society for the Promotion of Science.

\section{References}

Anderson TF, Voorhees JJ (1980) Psoralen photochemotherapy of cutaneous disorders. Annu Rev Pharmacol Toxicol 20:235-257.

Bohuslavizki KH, Hänsel W, Kneip A, Koppenhöfer E, Niemöller E, San- mann K (1994) Mode of action of psoralens, bezofurans, acridinons and coumarins on the ionic currents in intact myelinated nerve fibers and its significance in demyelinating diseases. Gen Physiol Biophys 13:309-328.

Bourgaud F, Hehn A,Larbat R, Doerper S, Gontier E, Kellner S, Matern U (2006) Biosynthesis of coumarins in plants: a major pathway still to be unravelled for cytochrome P450 enzymes. Phytochemistry Rev 5:293-308.

Bradford MM (1976) A rapid and sensitive method for the quantitation of microgram quantities of protein utilizing the principle of protein-dye binding. Anal Biochem 72:248-254.

Brown SA, Steck W (1973) 7-Demethylsuberosin and osthenol as intermediates in furanocoumarin biosynthesis. Phytochemistry 12:1315-1324.

Cole RS (1970) Light-induced cross-linking of DNA in the presence of a furanocoumarin (psoralen): Studies with phage $\lambda$, E. coli, and mouse leukemia cells. Biochim Biophys Acta 217:30-39.

Ekiert H, Chołoniewska M, Łojkowska E (2001) Accumulation of furanocoumarins in Ruta graveolens L. shoot culture. Biotechnol Lett 23:543-545.

Fouin-Fortunet H, Tinel M, Descatoire V, Letteron P, Larrey D, J Geneve J, Pessayre D (1986) Inactivation of cytochrome P-450 by the drug methoxsalen. J Pharmacol Exp Ther 236:237-247. 
Franke K, Porzel A, Masaoud M, Adam G, Schmidt J (2001) Furanocoumarins from Dorstenia gigas. Phytochemistry 56:611-621.

Frick S, Kutchan TM (1999) Molecular cloning and functional expression of $O$-methyltransferases common to isoquinoline alkaloid and phenylpropanoid biosynthesis. Plant J 17:329-339.

Hahlbrock K, Scheel D (1989) Physiology and molecular biology of phenylpropanoid metabolism. Annu Rev Plant Physiol Plant Mol Biol 40:347-369.

Hamerski D, Beier RC, Kneusel RE, Matern U, Himmelspach K (1990) Accumulation of coumarins in elicitor-treated cell suspension cultures of Ammi majus. Phytochemistry 29: 1137-1142.

Hamerski D, Matern U (1988a) Biosynthesis of psoralens. Psoralen 5-monooxygenase activity from elicitor-treated Ammi majus cells. FEBS Lett 239:263-265.

Hamerski D, Matern U (1988b) Elicitor-induced biosynthesis of psoralens in Ammi majus L. suspension cultures: Microsomal conversion of demethylsuberosin into $(+)$ marmesin and psoralen. Eur J Biochem 171:369-375.

Hamerski D, Schmitt D, Matern U (1990) Induction of two prenyltransferases for the accumulation of coumarin phytoalexins in elicitor-treated Ammi majus cell suspension cultures. Phytochemistry 29:1131-1135.

Hauffe KD, Hahlbrock K, Scheel D (1986) Elicitor-stimulated furanocoumarin biosynthesis in cultured parsley cells: S-adenosyl-L-methionine: bergaptol and S-adenosyl-L-methionine: xanthotoxol O-methyltransferases. Z Naturforsch 41c:228-239.

He K, Iyer KR, Hayes RN, Sinz MW, Woolf TF, Hollenberg PF (1998) Inactivation of cytochrome P450 3A4 by bergamottin, a component of grapefruit juice. Chem Res Toxicol 11:252-259.

Hehmann M, Lukačin R, Ekiert H, Matern U (2004) Furanocoumarin biosynthesis in Ammi majus L. :cloning of bergaptol O-methyltransferase. Eur J Biochem 271:932-940.

Ishikawa A, Kitamura Y, Ozeki Y, Ito Y, Yamada A, Watanabe M (2005) Post-stress metabolism involves umbelliferone production in anthocyanin-producing and non-producing cells of Glehnia littoralis suspension cultures. J Plant Physiol 162:703-710.

Ishikawa A, Kitamura Y, Ozeki Y, Watanabe M (2007) Different responses of shoot and root cultures 
of Glehnia littoralis to yeast extract. J Nat Med 61:30-37

Kawase M, Sakagami H, Motohashi N, Hauer H, Chatterjee SS, Spengler G., Vigyikanne AV, Molnár A, Molnár J (2005) Coumarin derivatives with tumor-specific cytotoxicity and multidrug resistance reversal activity. In Vivo 19:705-712.

Kitajima J, Okamura C, Ishikawa T, Tanaka Y (1998) Coumarin glycosides of Glehnia littoralis root and rhizoma. Chem Pharm Bull 46:1404-1407.

Kitamura Y, Ikenaga T, Ooe Y, Hiraoka N, Mizukami H (1998) Induction of furanocoumarin biosynthesis in Glehnia littoralis cell suspension cultures by elicitor treatment. Phytochemistry 48:113-117.

Kitamura Y, Ohta M, Ikenaga T, Watanabe M (2002) Responses of anthocyanin-producing and non-producing cells of Glehnia littoralis to radical generators. Phytochemistry 59:63-68.

Królicka A, Staniszewska I, Bielawski K, Maliński E, Szafranek J, Łojkowska E (2001) Establishment of hairy root cultures of Ammi majus. Plant Sci 160:259-264.

Larbat R, Kellner S, Specker S, Hehn A, Gontier E, Hans J, Bourgaud F, Matern U (2007) Molecular cloning and functional characterization of psoralen synthase, the first committed monooxygenase of furanocoumarin biosynthesis. J Biol Chem 282:542-554.

Maisch T (2007) Anti-microbial photodynamic therapy: useful in the future? Lasers Med Sci 22:83-91.

Milesi S, Massot B, Gontier E, Bourgaud F, Guckert A (2001) Ruta graveolens L .: a promising species for the production of furanocoumarins. Plant Sci 161:189-199.

Miura H, Kitamura Y, Ikenaga T, Mizobe K, Shimizu T, Mikio M, Kato Y, Yamada T, Maitani T, Goda Y (1998) Anthocyanin production of Glehnia littoralis callus cultures. Phytochemistry 48: 279-283.

Mo EK, Sung CK (2006) The effect of phenylethyl alcohol on PAL mRNA and enzyme activity in strawberries. Postharvest Biol Technol 42:290-292

Murashige T, Skoog F (1962) A revised medium for rapid growth and bioassay with tobacco tissue cultures. Physiol Plant 15:473-497. 
Ozçelik B, Kusmenoglu Ş, Turkoz S, Abbasoglu U (2004) Antimicrobial activities of plants from the Apiaceae. Pharm Biol 42:526-528.

Sasaki H, Taguchi H, Endo T, Yosioka I (1980) The constituents of Glehnia littoralis FR. SCHMIDT et MIQ. structure of a new coumarin glycoside, osthenol-7-O- $\beta$-gentiobioside. Chem Pharm Bull 28:1847-1852.

Sidwa-Gorycka M, Królicka A, Kozyra M, Głowniak K, Bourgaud F, Łojkowska E (2003) Establishment of a co-culture of Ammi majus L. and Ruta graveolens L. for the synthesis of furanocoumarins. Plant Sci 165:1315-1319.

Smith ML, Gregory P, Bafi-Yeboa NFA, Arnason JT (2004) Inhibition of DNA polymerization and antifungal specificity of furanocoumarins present in traditional medicines. Phytochem Photobiol 79:506-509.

Stevenson PC, Simmonds MSJ, Yule MA, Veitch NC, Kite GC, Irwin D, Legg M (2003) Insect antifeedant furanocoumarins from Tetradium daniellii. Phytochemistry 63:41-46.

Strauss U, Wissel K, Jung S, Wulff H, Hänsel W, Zhu J, Rolfs A, Mix E (2000) $\mathrm{K}^{+}$ channel-blocking alkoxypsoralens inhibit the immune response of encephalitogenic $\mathrm{T}$ line cells and lymphocytes from Lewis rats challenged for experimental autoimmune encephalomyelitis. Immunopharmacology 48:51-63.

Taguchi G, Fujikawa S, Yazawa T, Kodaira R, Hayashida N, Shimosaka M, Okazaki M (2000) Scopoletin uptake from culture medium and accumulation in the vacuoles after conversion to scopolin in 2,4-D-treated tobacco cells. Plant Sci 151:153-161.

Takeda J, Ito Y, Maeda K, Ozeki Y (2002) Assignment of UVB-responsive cis-element and protoplastization (dilution-) and elicitor-responsive ones in the promoter region of a carrot phenylalanine ammonia-lyase gene (gDcPAL1). Phytochem Photobiol 76:232-238.

Tietjen KG, Hunkler D, Matern U (1983) Differential response of cultured parsley cells to elicitors from two non-pathogenic strains of fungi. 1. Identification of induced products as coumarin derivatives. Eur J Biochem 131:401-407.

Tietjen KG, Matern U (1983) Differential response of cultured parsley cells to elicitors from two 
non-pathogenic strains of fungi. 2. Effects on enzyme activity. Eur J Biochem 131:409-413.

Wendorff H, Matern U (1986) Differential response of cultured parsley cells to elicitors from two non-pathogenic strains of fungi. Microsomal conversion of (+)-marmesin into psoralen. Eur J Biochem 161:391-398.

Wong PYY, Kitts DD (2006) Studies on the dual antioxidant and antibacterial properties of parsley (Petroselinum crispum) and cilantro (Coriandrum sativum) extracts. Food Chemistry 97:505-515.

Yuan Z, Tezuka Y, Fan W, Kadota S, Li X (2002) Constituents of the underground parts of Glehnia littoralis. Chem Pharm Bull 50:73-77.

Zangerl AR, Berenbaum MR (1994) Spatial, temporal, and environmental limits on xanthotoxin induction in wild parsnip foliage. Chemoecology 5-6:37-42. 
Table 1. Substrate specificity of recombinant $G$. littoralis bergaptol $O$-methyltransferase (BMT)

\begin{tabular}{|c|c|c|c|c|}
\hline Enzyme & Substrate & Product & $K \mathrm{~m} \quad(\mu \mathrm{M})$ & $V \max (p k a t / m g$ protein) \\
\hline BMT & berga & bergapten & 12.9 & 3.38 \\
\hline $\mathrm{XMT}^{\mathrm{a}}$ & anthotoxol & xanthotoxin & $-^{c}$ & - $^{\circ}$ \\
\hline $\mathrm{COMT}^{\mathrm{b}}$ & caffeic acid & ferulic acid & $-^{c}$ & $-^{c}$ \\
\hline \multicolumn{5}{|c|}{$\begin{array}{l}{ }^{\mathrm{a}} \text { xanthotoxol } O \text {-methyltransferase; }{ }^{\mathrm{b}} \text { caffeic acid } O \text {-methyltransferase; }{ }^{\mathrm{c}} \text { Since } \\
\text { enzyme activity was not detected, neither Km value nor Vmax was determined. Assay } \\
\text { of BMT activity is referenced as a legend in Fig. } 3 . \text { XMT activity was assayed same } \\
\text { as BMT activity except substrate. For COMT activity, incubation was carried out at } 32^{\circ} \\
\text { C in the } 100 \mathrm{mM} \mathrm{KPi \quad (pH} \mathrm{7.5).}\end{array}$} \\
\hline
\end{tabular}

Table 2. Dose dependency of phenylethyl alcohol (PEA) on phenylalanine ammonia-lyase (PAL) and bergaptol $O$-methyltransferase (BMT) activities.

\begin{tabular}{|c|c|c|}
\hline PEA (mM) & PAL (pkat/mg protein) & BMT (pkat/mg protein) \\
\hline 0 & 10.7 & 1.0 \\
\hline 0.5 & 9.6 & 1.1 \\
\hline 1 & 5.5 & 1.0 \\
\hline 5 & 1.1 & 1.1 \\
\hline
\end{tabular}

Proteins were extracted from the cells treated with various concentrations of PEA for $9 \mathrm{~h}$. The method of enzyme assays is referenced as a legend in Fig. 3. 
Fig. 1 Biosynthetic pathway leading to bergapten

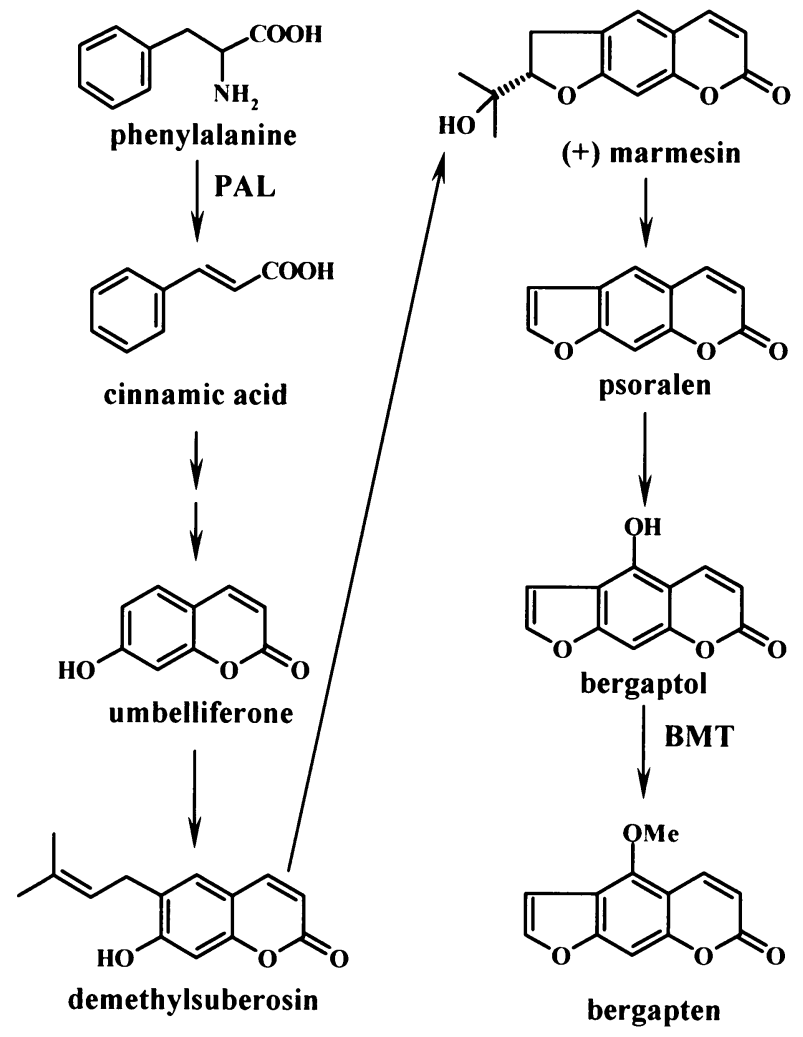


Fig. 2 Time course of the uptake of psoralen and production of bergapten in the culture medium (upper) and cells (lower). Cultured medium and cells were collected separately at 3,6, 9 and $24 \mathrm{~h}$ after administration of psoralen. Data are mean \pm S.D. $(n=3)$.

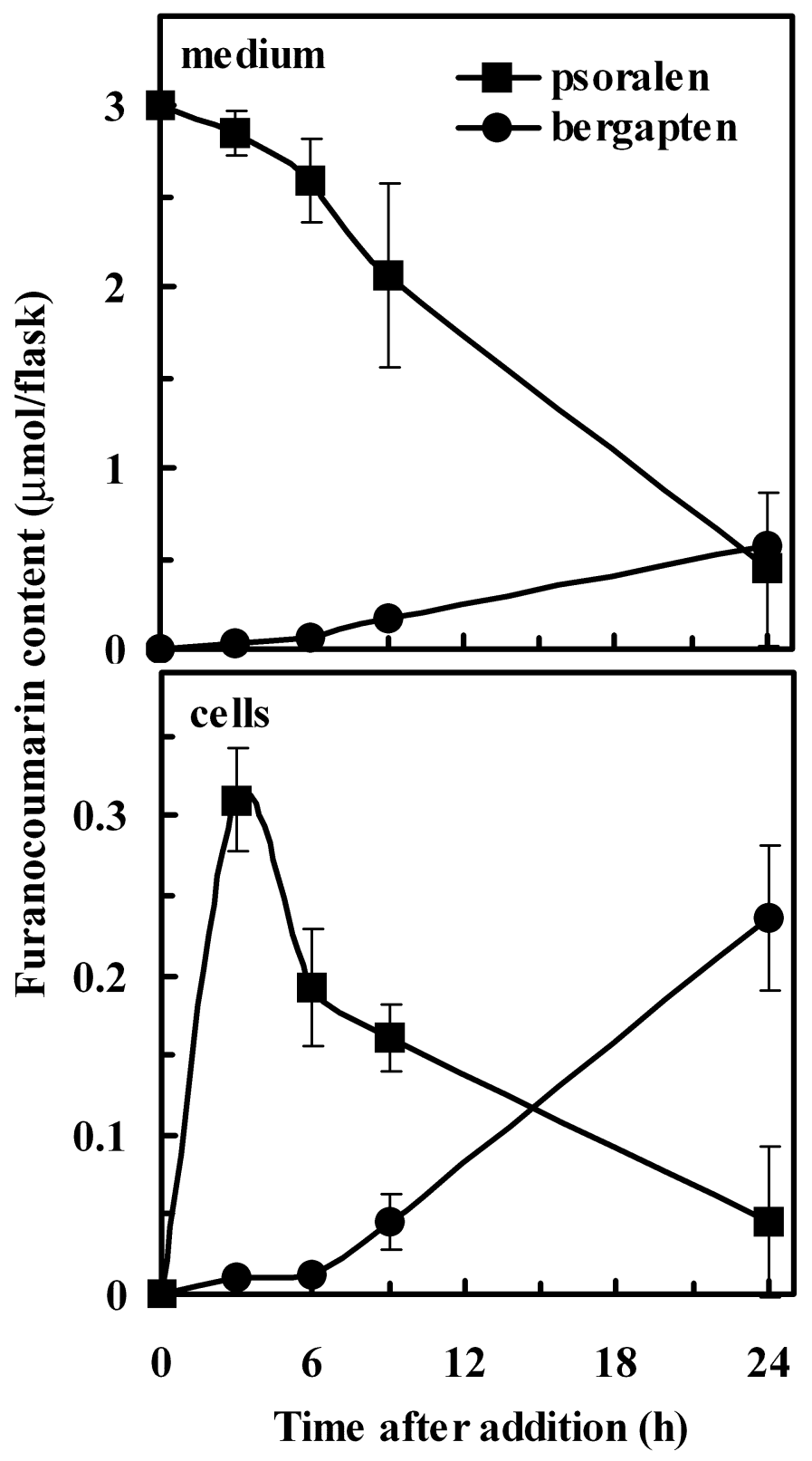


Fig. 3 Time course of the uptake of umbelliferone and production of skimmin in the cell cultures. Cultured medium and cells were collected separately at 3,6,9 and $24 \mathrm{~h}$ after administration of umbelliferone. Umbelliferone and skimmin were analyzed in the medium and in the cells, respectively. Data are mean \pm S.D. $(n=3)$.

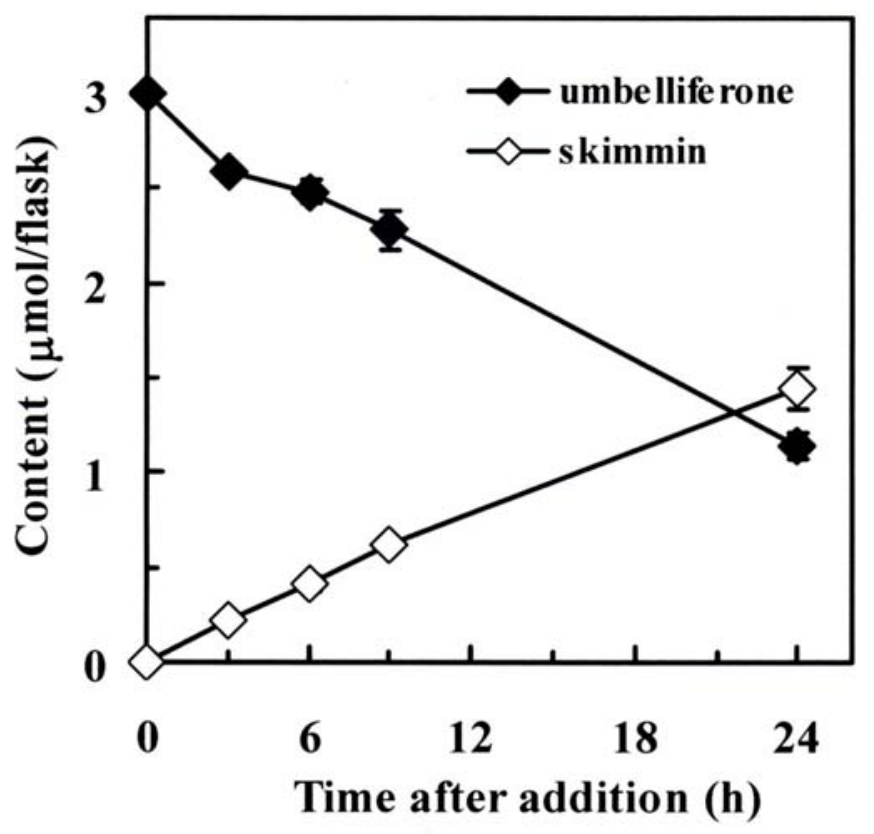


Fig. 4 Time-course analysis of PAL (upper) and BMT (lower) activities in suspension cells, exogenously supplied with individual furanocoumarins. Crude extracts were prepared from the cells using $100 \mathrm{mM}$ potassium phosphate buffer (pH 8.0). For the assay of PAL, crude extract was incubated with $0.5 \mu \mathrm{mol} \mathrm{L}$-phenylalanine as substrate at $30^{\circ} \mathrm{C}$ for $60 \mathrm{~min}$. For the assay of BMT, crude extract was incubated with $0.25 \mathrm{mM}$ bergaptol, $0.2 \mathrm{mM} \mathrm{SAM}$ and $20 \mathrm{mM}$ sodium ascorbate, at $40^{\circ} \mathrm{C}$ for 60 min. For HPLC quantification, reaction products of PAL and BMT were extracted with ether and ethyl acetate, respectively. Data are mean \pm S.D. $(n=3)$.

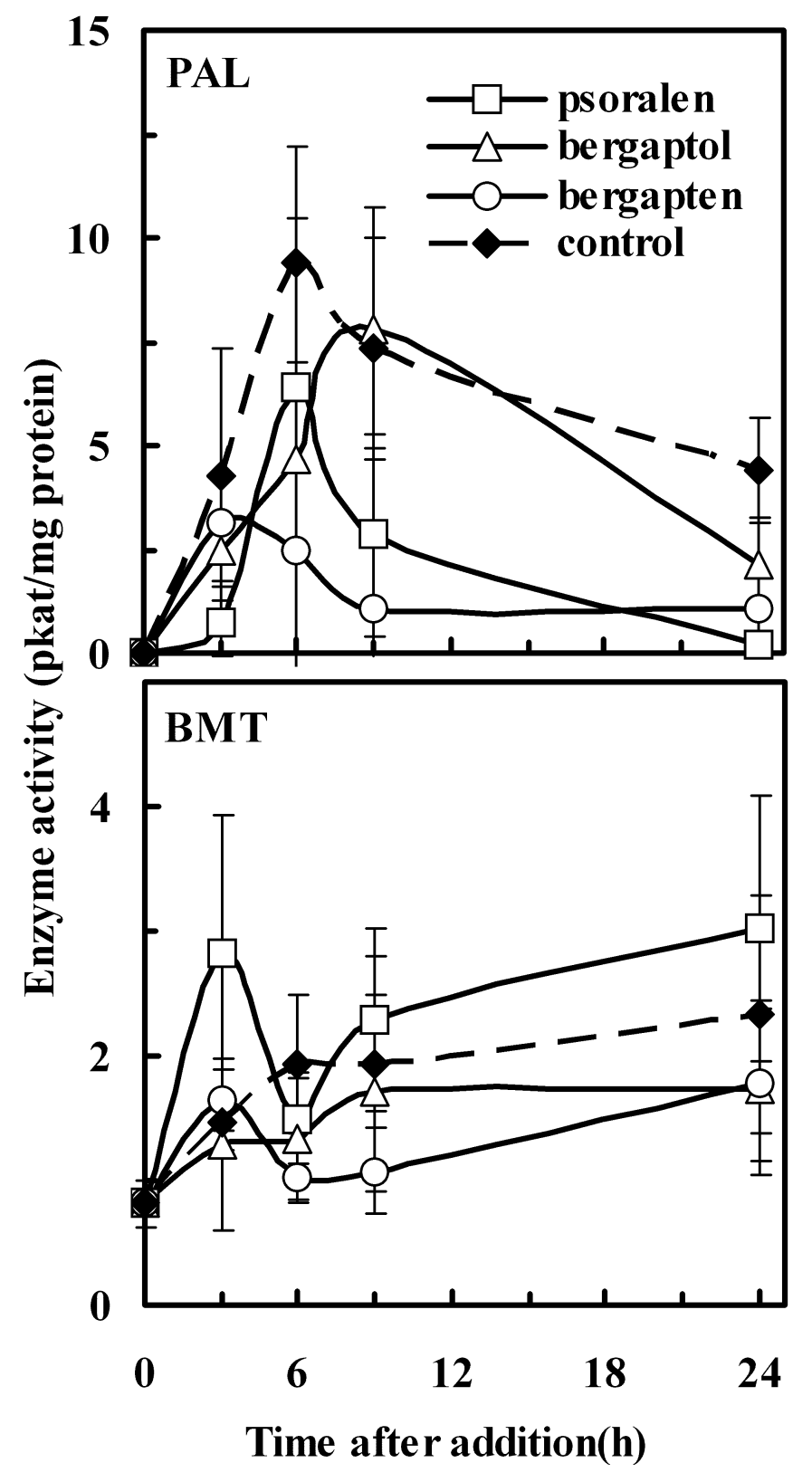


Fig. 5 Time courses of gene expression of PAL and BMT in G. littoralis suspension cells supplied with furanocoumarins. Results are presented only for psoralen-administered and control cells because similar results were obtained for cells fed with other coumarins. Total RNA was extracted from $0.1 \mathrm{~g}$ of cells, and RT-PCR was performed with GIPAL, GIBMT and GIUBI specific primers for amplification of 255, 236 and $181 \mathrm{bp}$ fragments, respectively. $U B I$ was used as a control.

\begin{tabular}{|c|c|c|c|c|c|c|c|c|c|}
\hline & & & ontro & & & & psor: & aler & \\
\hline Time (h) & & 3 & 6 & 9 & 24 & 3 & 6 & 9 & \\
\hline PAL & & $=$ & $=$ & $=$ & & $=$ & $=$ & $=$ & \\
\hline BMT & & $=$ & $=$ & $=$ & $=$ & $=$ & $=$ & $=$ & \\
\hline$U B I$ & & & & & & $=$ & - & & \\
\hline
\end{tabular}

